\title{
Gênero e sexualidade: fragmentos de identidade masculina nos tempos da Aids
}

\author{
Gender and sexuality: \\ fragments of male identity in the Aids era
}

Murilo Peixoto da Mota 1

\footnotetext{
1 Núcleo de Estudose Projetos em Comunicação, Escola de Comunicação, Universidade Federal do Rio de Janeiro. Av. Pasteur, Campus da Praia Vermel ha, sala 120, Botafogo, Rio de Janeiro, RJ. mpmota@agentel.com.br
}

\begin{abstract}
A bstract This paper focuses on specific aspects of male sexual ity and how this sexual identity is built in the Aids era, based on conversations with low-income youth, ages 14-21 years, living in Greater Metropolitan Rio de Janei ro. We examine how Aids is percei ved and investigate sexuality in this epidemic context. The goal is to provide concrete data to support a prevention campaign and contribute to preventive policies in Brazilian society. The proposal is based on the sexual identity of this gender/age group, comparing their reports on sexual practice. We used a partially open-ended interview protocol. We focus on the way young males choose their sexual identity under the premise that this is how men can become the channel for Aids transmission. Our research was thus based on gender and sexual identity as categories. Our results indicate that for a young man, "being a man" means having an active sexual life, thus creating a stereotype placing them at risk for HIV transmission.

Key words Aids; Adolescents; Gender; Gender Identity
\end{abstract}

Resumo Este trabal ho busca entender alguns aspectos da sexualidade masculina, bem como as formas como se organiza a construção da identidade sexual no contexto da epidemia de Aids, a partir da fala de jovens de baixa renda entre 14 e 21 anos, moradores da área metropolitana do Rio de Janeiro. Nossa proposta consi ste em articular al guns aspectos do gênero masculino, subsidiados pela identidade sexual revelada pel os suj eitos, estabel ecendo um confronto com os relatos sobre a prática sexual, procedimento que se tornou possível a partir de entrevista qualitativa com uso de um rotei ro semi-estruturado. Julgamos de fundamental importância a análise das maneiras como se dá a escol ha do obj eto sexual em relação à construção da identidade, tendo como referência aquele que foi consi derado o pivô no que diz respei to à transmissão da Aids: o homem. Neste sentido, nossa investi gação se pautou nas categorias gênero e identi dade sexual. Como resultado, observamos que, na concepção destes jovens, ser homem é desempenhar a prática sexual, cumprindo, assi m, os papéi s destinados ao gênero masculino, reproduzindo um estereóti po que os coloca em situação de risco.

Palavras-chave Aids; Adolescentes; Sexo; Identidade Sexual 


\section{Introdução}

Este estudo busca entender al guns aspectos da sexualidade masculina, bem como as formas como se organiza a construção da identidade sexual no contexto da epidemia de Aids, com base na fala de jovens de baixa renda entre $14 \mathrm{e}$ 21 anos, moradores da área metropolitana do Rio de Janeiro. Tem por objetivo fornecer dados empíricos que sirvam de base para o acompanhamento e criação de campanhas de prevenção, além de tentar contribuir para o planejamento de políticas de intervenção à Aids em nossa sociedade.

Nossa proposta consiste em levantar a discussão dos papéis de gênero masculino valendo-nos da identidade sexual revelada pelos sujeitos pesquisados, estabelecendo um confronto com os relatos sobre a prática sexual. Buscamos também captar a diversidade de desejos e fantasias sexuais, relacionando-os com a autoidentidade, níveis de informação e conhecimento sobre o HIV/Aids, assim como as mudanças de atitudes em relação à epidemia.

A discussão tomou por base tanto pesquisas antropológicas, quanto sociológicas, que permitiram perceber que as categorias de identidade (homossexual, heterossexual e bissexual) têm significações culturais relativas no contexto da prática sexual, principalmente se analisarmos as percepções de tais práticas em nossa cultura. Se a identidade sexual envolve questões simbólicas e representações complexas, como generalizar e unificar condutas e identidades com o propósito de separar os grupos que são mais suscetíveis ao risco dos que têm menor suscetibilidade, como tentou a ciência médica?

O trabalho justifica-se em função da necessidade de se repensar não só as visões que envolvem a Aids, como também as questões implicadas no contexto da história sexual dos sujeitos envolvidos no estudo. Neste sentido, julgamos de fundamental importância a análise das maneiras como se dá a escolha do objeto sexual em relação à construção da identidade, tendo como referência aquele que foi considerado o pivô na questão da transmissão da Aids: o homem. Nossa investigação se pauta nas categorias gênero e identidade sexual.

Pensar o gênero masculino e a identidade sexual remete-nos a questões intimamente ligadas ao padrão de comportamento sexual do brasileiro e suas representações sobre a sexualidade, que é diferente de região para região do país, de classe social para classe social e, sobretudo, de um momento histórico em relação a outro. Ademais, quando nos voltamos para a tentativa de compreensão do contexto da Aids no comportamento sexual masculino, percebemos várias contradições e conflitos que apontam para uma complexidade histórica e que, evidentemente, ultrapassam aquel e conjunto de classificações expressadas para identificar os grupos mais suscetíveis ao contágio do HIV/Aids, como o chamado homossexual masculino.

Optamos por enfocar a construção cultural do gênero e da sexualidade no contexto de jovens masculinos de baixa renda moradores na área metropolitana do Rio de Janeiro, com o intuito de fornecer subsídios para a prevenção do HIV/ Aids nestes sujeitos.

\section{Contexto do estudo}

Observando as classificações epidemiológicas dadas e analisando especificamente as práticas sexuais cotidianas nomeadas como homossexualidade, bissexualidade e heterossexualidade masculina, esbarramos numa realidade em que, como define Costa (1992), a homogeneidade teorizada nestas categorias difere da heterogenei dade vivida. Se rel ativizarmos o contexto erótico masculino, no qual os papéis de gênero possuem regras morais relativamente flexíveis em nível das atividades sexuais, e 'ser homem' está também construído pela idéia de atividade sexual intensa, perceberemos, sem muita dificuldade, que ser homossexual, bissexual ou heterossexual depende do significado erótico que o sujeito atribui à sua prática sexual e à forma como percebe os papéis de gênero em seu contexto.

Ao nos referirmos à categoria gênero, apontamos para um debate que diz respeito à concepção do que é ser masculino e feminino, homem e mulher na sociedade, aspecto que interpela a experiência sexual dos sujeitos, modela o mundo dos significados eróticos, as transações sexuais, a realização do desejo e, em algumas circunstâncias, a própria obtenção do gozo. Nesse sentido, o gênero é um aspecto maleável do eu que torna possível que se reconheçam não apenas as semelhanças e igualdades existentes entre os sujeitos sociais - homem e mulher -, mas os padrões de coerência cultural que existem em razão mesmo da diferença que os separa, as contradições lógicas e emocionais que fluem desta coexistência binária (Scott, 1989; Heilborn, 1994).

É fato que, além das características biológicas que promovem a diferença dos sexos, existe o gênero. Trata-se de um complexo de determinações e características que designam so- 
cialmente o que é ser masculino e feminino em determinada cultura. Assim, o corpo recebe uma significação sexual que é definida como referência sobre o que é ser masculino e feminino. Tal significação aparece como norma, valores, percepções, representações que acompanham a vida dos sujeitos (Giffin, 1994).

Neste sentido, gênero aciona informações sobre os homens, apesar de os estudos sobre essa categoria darem atenção especial ao lugar da mulher na sociedade, afirmando a posição de que as relações entre os sexos são sociais e culturalmente construídas, e que há diferenças nas articulações de poder. Ou seja, os estudos de gênero incluem temas que são, em geral, considerados caracteristicamente ligados às mulheres, mas não se limitam a eles. Assim, o gênero, enfocado como categoria sociológica, traz novas possibilidades para se pensar a questão do homem e da mulher, articulando as relações sujeito e sociedade (Scott, 1989). Ao tentarmos incluir o homem neste debate, vemos a importância de se questionarem os papéis sociais que configuram o modelo masculino em nossa cultura, percebendo como os homens se vêem nesses papéis, como os representam e constroem a própria identidade.

Levando-se em conta os papéis sociais legados ao homem em nossa cultura, observamos que ser homem não representa a mera oposi ção ao ser mulher, mas ao ser um 'veado', homossexual, 'maricas', 'corno', 'bicha' -, figuras que articulam representações de feminilidade, fraqueza, impotência, subordinação, passividade (Parker, 1991). Esse fato deixa ver as formas como o homem é engendrado nesta sociedade de tradição patriarcal, ou seja, a partir de valores hegemônicos e estruturas de poder que o diferenciam da mulher e que ao mesmo tempo moldam seu comportamento.

Os homens aprendem a valorizar a atividade sexual como algo que legitima sua identidade masculina; ser homem é desempenhar o papel de quem domina e 'penetra' outros. É muito comum, por exemplo, jovens em iniciação sexual realizarem as 'meinhas', situação em que um penetra o outro trocando de posição. Entre casais (homens e mulheres) adolescentes, também é comum o coito anal como preservação da virgindade e método contraceptivo (Daniel \& Parker, 1991).

Diante deste quadro, há algo que chama nossa atenção quando colocamos em pauta Aids e erotismo, quer seja, o significado que alguns homens dão às práticas sexuais que, ao contrário de pautarem-se nas chamadas identidades sexuais (homo, hetero ou bissexual), são movidas pelo tesão. Cabe lembrar, além dis- so, que a casa de prostituição (termas, 'inferninhos', casas de massagens etc.) representa, na vida sexual do brasileiro - seja ele solteiro ou casado, adulto ou adolescente -, algo visto como motivo de orgulho. É “lá onde se aprende a ser homem", diz o senso comum para os jovens em iniciação sexual. Procurar as prostitutas é não só uma conduta aceita como sendo 'coisa de homem', como também justificada como se constituindo numa tentativa de realização de fantasias sexuais, cujas esposas ou mães não poderiam realizar.

Queremos demonstrar, por meio deste estudo e com base em referências teóricas de outros, que o comportamento sexual privado do homem não se confunde com a sua identidade sexual pública, heterossexual, anunciada e representada, o que torna a prevenção do HIV/ Aids ainda mais problemática. De fato, todo esse contexto simbólico parece encobrir verdades pouco ditas, cujas racionalizações equivocadas, as quais oscilam entre o ideológico e o biológico, ainda estão para ser avaliadas pela história da Aids no Brasil. A questão que envolve o ser homossexual, heterossexual ou bissexual em nossa sociedade pode passar por outras que nem sempre são racionalizadas em nível do senso comum, nem mesmo percebidas como classificações identificadoras. Ou seja, homens podem ter relações com outros homens e com mulheres ao mesmo tempo, sem que isso seja associado à identidade sexual na forma como é colocada pela ciência médica.

Neste sentido, observando as classificações epidemiológicas dadas e analisando especificamente as práticas da homossexualidade, bissexualidade e heterossexualidade masculina no cotidiano, esbarramos numa realidade segundo a qual, como já vimos com Costa (1992), a homogenei dade teorizada nestas categorias difere da heterogeneidade vivida. Isto significa dizer que, se colocarmos em questão o contexto erótico cotidiano masculino, cujos papéis sociais possuem regras morais relativamente flexíveis em nível das atividades sexuais, perceberemos, sem muita dificuldade, que ser homossexual, bissexual ou heterossexual depende do significado erótico que o sujeito atribui à sua prática sexual e à forma como percebe os papéis de gênero em seu contexto.

A questão da classificação da identidade sexual e Aids, mais que um elemento-chave no contexto epidêmico, aparece como um aspecto estruturante nas representações sociais, principalmente quando se tratam os termos homossexual ou homossexualidade como identidades do sujeito. Percebe-se que a questão da identidade sexual pode ser uma construção in- 
timamente ligada a práticas sexuais que se apresentam como uma expansão de estilo de vida, em virtude de desejos sexuais cada vez mais específicos, que assegura para os sujeitos um contexto de identidade coletiva, no qual encontram os pares com quem vão manter relações. Isto é, observa-se que a identidade está ligada às maneiras como o sujeito se vê e ao lugar em que a sociedade o coloca. Portanto, além destas identidades sexuais já conhecidas, há outras.

Diante da Aids, a questão da identidade sexual ganhou contornos específicos de discriminação e preconceito, principalmente para o que foi denominado prática homossexual. Retomo Costa (1992:22), quando o psicanalista questiona as categorias de identidade, dizendo que são inadequadas enquanto demarcação de comportamentos sociais distintos. Neste sentido, ele propõe uma nova denominação, o ‘homoerotismo', como uma referência às práticas sexuais de homens que desejam outros homens. O termo, lançado em 1992, além de sugerir uma proposta ético-teórica à noção de homossexualismo e homossexualidade, abre outras possibilidades analíticas. O próprio autor acrescenta que interpretar a idéia de homossexualidade como uma essência, uma estrutura ou denominador sexual comum a todos os homens homoeróticos é incorrer num grande erro etnocêntrico. Penso que a noção de homoerotismo tem a vantagem de tentar afastarse tanto quanto possível desse engano. Primeiro, porque exclui toda e qualquer alusão a doença, desvio, anormalidade, perversão etc., que acabaram por integrar o sentido da palavra homossexual. Segundo, porque nega a idéia de que existe algo como 'uma substância homossexual' orgânica ou psíquica comum a todos os homens com tendências homoeróticas. Terceiro, enfim, porque o termo não possui a forma substantiva que indica identidade, como no caso do homossexualismo, do qual derivou o substantivo homossexual. Para o autor, as vivências sexuais não cabem em rígidos modelos classificatórios de identidade previamente estabelecidos. Há, segundo ele, um pressuposto, uma naturalização e universalização de uma prática difundida como sendo a expressão única e normal das relações sexuais: a heterossexualidade. Nesta perspectiva, o homoerotismo corresponde a uma subjetividade e a uma realidade lingüística e não a uma condição natural e biológica.

Observa-se, então, que o comportamento no contexto do cotidiano vai muitas vezes de encontro àquilo que se convencionou chamar de heterossexual masculino como uma refe- rência à identidade sexual. Além do mais, a identidade não parece ser uma questão para o chamado heterossexual, cuja identidade sexual já está, de certa maneira, dada socialmente pelos papéis de gênero. Está colocada, sim, para o sujeito cujo comportamento difere da norma estabelecida para o que se considera ser homem. Portanto, a identidade, neste caso, aponta para quem é a diferença, do ponto de vista da visibilidade; daí homens com trejeitos femininos serem facilmente classificados. De qualquer modo, a Aids tem possibilitado a descoberta do quanto a sexualidade favorece o desenvolvimento de estilos de vida variados.

Se estamos trabalhando com jovens de 14 a 21 anos - justamente o período em que se inicia a prática sexual num tempo de epidemia sexualmente transmissível -, julgamos que o aprofundamento de nosso trabalho deve residir nos domínios do erótico na vida sexual diária, já que se trata de uma fase em que nem sempre o proibido é desvalorizado e o permitido aceito como definição na construção da sua identidade. Se em determinadas ocasiões - não muito particulares ou privadas -, transgredir a norma sexual pode ser a regra aceita como demonstração de eficiência sexual, conduta própria do papel masculino em nossa cultura, que dirá para os jovens em iniciação sexual?

Aids e erotismo apontam, portanto, para uma reflexão específica: o modelo de prevenção deve levar em conta as sutilezas do universo sexual, no qual às classificações públicas sobre o sexo podem corresponder, no mundo da experiência erótica, condutas contraditórias; o comportamento 'desviante', por exemplo, pode ser encarado como um estilo, aspecto das regras do jogo (da diferença) ou o próprio modelo que expressa um 'rito de passagem'.

Mais uma vez, o mundo privado da sexualidade parece revisitado, mostrando que há ocultamento, simulações e representações de práticas sexuais entre os sujeitos feminino ou masculino, em relações causais ou regulares, dentro ou fora do casamento. Enfim, as pesquisas sociais acerca do comportamento sexual em tempos de Aids estão desvelando o jogo erótico do cotidiano sexual, que parece estabelecer, de um lado, maior flexibilidade de práticas no contexto do espaço privado das relações, e, por outro, rigidez no âmbito público para os ol hares sempre atentos da Igreja e de outros aparelhos ideológicos.

Vemos, enfim, confirmar-se a necessidade de que o homem e suas práticas sexuais sejam mais bem estudados nesse processo epidêmico do HIV/ Aids em nossa sociedade. 


\section{Material e método}

Buscamos uma diversidade de sujeitos, tentando abranger o recorte previamente definido: faixa etária (14 a 21 anos) e condição sócioeconômica. A faixa etária foi definida tendo como base nosso interesse em investigar aqueles que se tornaram sexualmente ativos durante $o$ período em que o HIV/Aids já havia se tornado motivo de preocupação no Brasil. Mas o que justifica o uso de tais parâmetros para a seleção da amostra é principalmente a vulnerabilidade aos riscos de contágio de HIV/Aids em que se encontram muitos destes jovens, vulnerabilidade esta relacionada ao comportamento sexual, a condições objetivas do meio social e ao grau de consciência que possuem em relação ao próprio corpo. E é neste sentido que Ayres (1996) chama a atenção para alguns aspectos mais particulares que expõem esta população jovem à Aids, fazendo del a prioridade nos estudos sócio-antropológicos. Dentre tais aspectos, destacam-se: limites culturais próprios para a fixação simbólica das informações; necessidade de transgredir e experimentar riscos; sistema educacional desestimulante; desagregação familiar; auto-estima baixa e exposição à violência.

Utilizamos a metodologia qualitativa, mediante um roteiro semi-estruturado para as entrevistas que, por sua vez, contemplaram os seguintes pontos: a) identificação: idade, renda familiar, trabal ho remunerado, lazer; b) sexualidade: experiências sexuais (história de vida sexual), auto-identidade sexual, fidelidade, prática ou sofrimento de violência sexual, práticas eróticas (desejos e fantasias), tipo de relacionamento afetivo (namoro, paixões, amor); c) conteúdos sobre papéis de gênero: atitudes e práticas consideradas masculinas ou femininas, relação com o corpo, ambições, aspirações de vida familiar; d) percepção sobre HIV/ Aids: conhecimentos sobre Aids (transmissão e prevenção), uso do preservativo, mudanças de comportamento e práticas sexuais em relação à prevenção, entendimento do que seja sexo seguro, negociação sexual.

O uso da metodologia qualitativa justificase por pretendermos investigar questões relacionadas à sexualidade e visão de mundo no contexto da epidemia de HIV/Aids. Consideramos que a utilização desta metodologia possibilita uma compreensão mais profunda de certos fenômenos sociais, levando-se em conta aspectos subjetivos da ação social em face da configuração das estruturas sócio-culturais e os fenômenos complexos e singularidades da vida sexual. Neste sentido, ao optarmos pelo qualitativo, assumimos, com tranqüilidade, 0 fato de tal escolha não ter sido arbitrária. Ao contrário, trata-se de uma opção na tentativa de estabelecermos uma interação com nosso material empírico.

Aids remete necessariamente ao complexo campo da sexualidade humana. Alguns autores (Minayo, 1993; Parker et al., 1995) têm discutido a questão metodológica nesta área, propondo algumas reflexões para o campo de investigação. A partir daí, percebemos que não basta estudar mudanças na expressão do comportamento sexual e de atitudes, mas examinar a relação dessas mudanças com questões mais profundas. Ou seja, é preciso investigar a forma como gênero e sexualidade masculina foram organizados e inter-relacionados dentro das relações sociais (Parker, 1991).

Entendemos que uma abordagem que trata da sexualidade e busca o entendimento da sua construção deve apoiar-se no pressuposto de que a maior relevância se concentra nos aspectos subjetivos da ação social, o que justifica trabalharmos com o método qualitativo neste estudo. Considerando-se esta perspectiva, alguns pontos merecem esclarecimentos: não cremos que a ciência tenha sido historicamente neutra e não nos convence o fato de que, para que haja ciência, a realidade deva traduzirse em dados objetivos, conforme apregoa o ideal positivista. Acreditamos que o real pode ser captado, não como um espelho que reflete a concretude virtual do fenômeno estudado, e sim pela concepção de que ele é relativo e que, se assim é, fazemos determinadas leituras do que chamamos de real. Ademais, esta postura assume todos os limites metodológicos que a questão envolve, pois, ao depararmo-nos com estes limites, entendemos estar encarando frente a frente a possibilidade de melhor poder lidar com os dados que colhemos.

As fal as de nossos entrevistados são plurais, refletem bem o quanto a questão sexo é tabu, segredo, proibição, repressão, pecado, orgulho, poder, vergonha, medo, desejo, erotismo, satisfação, moral, perigo, risco. A fala sobre o sexo está encoberta por sombras que envolvem fatos nunca ou pouco ditos, ou ditos de maneira a enganar os ouvidos do observador, do entrevistador, do ouvinte. Explicitam não apenas o que os sujeitos idealizam que são e como se percebem, como também estabelecem uma demarcação entre o lícito e o ilícito, o público e o privado, o aprovado e o reprovado, o cumprimento da lei ou sua transgressão.

Tomamos como objeto de investigação três recortes do problema. O primeiro, constituído por sujeitos auto-identificados como aqueles 
que assumiam o desejo de ter relações sexuais apenas com outros homens. Estes foram buscados através de indicações de amigos que freqüentavam as atividades do programa de prevenção de Aids, desenvolvido na organização não governamental denominada Associação Brasileira Interdisciplinar de Aids (Abia), cuja freqüência se caracterizava, em sua maioria, por jovens moradores da Baixada Fluminense e Zona Norte do Rio de Janeiro, com nível sócioeconômico baixo.

O segundo universo se constitui de jovens que transitavam assumidamente por práticas sexuais com homens e mulheres, e que se auto-identificavam como bissexuais, aos quais tivemos acesso também por intermédio do programa realizado pela Abia. Por fim, recrutamos jovens dentro de favelas, comunidades de baixa renda propriamente ditas, a fim de abordar homens que afirmavam relacionar-se com muIheres, auto-identificados como heterossexuais, os quais foram selecionados após contatos prévios com o Núcleo de Estudo de Saúde do Adolescente/Uerj e Associação de Moradores - Rocinha.

No que diz respeito às características sócioeconômicas, todos os jovens têm em comum o fato de trabalharem fora ou disporem de algum dinheiro com que possam ajudar em casa, além de se manterem. Neste sentido, foram abordados estudantes que recebem alguma ajuda de custo, vendedores ambulantes, contínuos, auxiliares de escritório, mecânicos, vitrinistas e biscateiros de pequenos serviços e reparos. O nível de escolaridade também é baixo, oscilando entre o primeiro grau completo e o segundo grau incompleto.

A escolaridade não foi definida como critério de nosso estudo, por não caracterizar aspectos de um determinado extrato social, fundamental para a definição do universo da pesquisa. Levamos em conta que a vida escolar está marcadamente fragmentada em todos os segmentos sociais e que, portanto, não seria um bom indicador para caracterizar a definição do objeto estudado.

Recrutamos jovens por meio de redes de amizades, ou seja, o primeiro contato com um informante abriria a possibilidade de outros contatos, formando uma rede. Buscamos jovens comuns, que não se destacassem por serem lideranças ou militantes de qualquer causa ideológica. Além disso, tivemos também o cuidado de não recrutar aqueles com inserção profissional em trabal hos preventivos da Aids ou que tivessem passado por algum tipo de treinamento metodológico específico em educação sexual nas instituições por nós contactadas.
A estratégia de recrutamento por redes de amizades ou redes de recrutamento direcionado de amostragem foi apontada por Parker (1994) como tendo o objetivo de superar as dificuldades inerentes à construção de amostras de probabilidade aleatória, que são representativas em estudos sobre práticas sexuais masculinas no contexto do HIV/ Aids. Segundo Parker (1994:60), “a maior parte do que se pode saber sobre risco sexual nessas populações deve basear-seem estratégi as direcionadas de amostragem, inevi tavel mente limitadas pel as opções disponíveis para o recrutamento de participantes".

O levantamento feito por redes de amizades justifica-se por se tratar de uma investigação que aborda aspectos que dizem respeito à prática e à história sexual, à percepção da auto-identidade sexual masculina. $O$ estudo, por si mesmo, apresenta limitações, por envolver a sexualidade de sujeitos muito jovens, ainda em fase de formação intelectual e moral. Além disso, interessa-nos não somente abordar aqueles que se identificam abertamente como gays, como também incluir os que possuem relações ocasionais com outros homens e também os que têm fantasias a esse respeito, sem a isso associarem uma identidade; consideramos ainda a sociabilidade sexual de jovens masculinos que usam serviços de profissionais do sexo, que têm relação com a esposa em casa e com outra mulher na rua, entre outras questões particulares, pouco ditas no cotidiano.

Com relação a este aspecto, não se conhece adequadamente as características da prática sexual masculina; além disso, não existe um perfil que possa transmitir uma visibilidade de determinados comportamentos sexuais, capaz de se traduzir em amostra. Portanto, é impossível trabalhar com amostras aleatórias que permitam generalizar conclusões. O caminho mais viável é abordar sujeitos pertencentes a grupos ou comunidades, conhecidos publicamente por suas manifestações sexuais e, a partir daí, recrutar informantes, que, como já foi dito, têm um vínculo indireto com tais grupos. A abordagem, feita por intermédio das redes, garante resultados sólidos capazes de refletir a diversidade dos sujeitos estudados (Giami, 1994).

Entrevistamos cinco jovens que se autoidentificaram como heterossexuais; dois, como homossexuais, etrês, como bissexuais. Usamos o mesmo critério de classificação de identidade utilizado pelos entrevistados, pautado em perguntas direcionadas. Além disso, como critério de seleção e número de entrevistas, levamos em conta o perfil definido anteriormente, até porque, num trabalho qualitativo, não se 
estabelece, quantitativamente, números de informantes. Tal perspectiva é percebida pela fala dos sujeitos, cujas representações simbólicas exprimem culturalmente as idéias de um grupo ou extrato social (Minayo, 1993).

Os contatos preliminares para entrada em campo se deram a partir de instituições que desenvolviam trabalhos com jovens, moradores em periferias e favelas do Grande Rio, em localidades que se caracterizavam por possuírem condições precárias de qualidade de vida.

Buscamos contatos com a Abia, que trabaIha com prevenção junto a homens que fazem sexo com homens; com a Associação de Moradores da Rocinha, que desenvolve um trabalho de profissionalização de jovens; com o Núcleo de Estudos de Saúde do Adolescente - NESA/ Uerj, que faz atendimento clínico, promoção e prevenção em saúde e sexualidade, entre outras áreas. Estas instituições, contudo, configuram-se, neste estudo, apenas como cenário no qual localizamos nossas redes de amizades (o 'amigo do amigo do amigo' vinculado, de alguma forma, a estas instituições, foi o nosso entrevistado).

Como tentamos demonstrar, a primeira ordem de questões diz respeito à nossa inserção no campo. Nossa tentativa foi a de não buscar as vias burocráticas para ter acesso aos informantes, ou seja, evitamos ofícios, memorandos, cartas e toda ordem de papéis que viessem estabelecer algum entrave na execução do trabalho. Apesar de nos posicionarmos academicamente com as coordenadorias institucionais, tentamos operacionalizar o trabalho a que nos propomos com autonomia e transparência.

\section{Resultados}

Para nossos entrevistados, a construção do gênero está ligada a atos de responsabilidade e a valores que estabelecem limites de espaço entre a sexualidade desempenhada com a muIher, em casa, e a exercida em outras circunstâncias. Há a representação de que homem que é homem deve ser bom pai, bom marido, trabalhador, e deve desempenhar bem o papel sexual. Observamos que possuem a consciência dos papéis masculinos exercidos culturalmente, os quais se configuram por intermédio do trabalho e do sexo. Aparentemente parece serIhes incômodo representar os papéis de correção e firmeza dentro de contextos de contradições sociais e culturais, nos quais, ao mesmo tempo em que se exige a expressão do gênero, requer-se flexibilidade na manutenção deste ideal de homem.
As falas expressam valores que ora denotam críticas ao estereótipo do gênero, ora assumem aspectos desse estereótipo. Esta ambigüidade denota o quanto há um modelo enraizado de homem, segundo o qual a relação com a parceria amorosa (com quem compartilha a casa) realiza-se em um contexto de contradição criada pelo ideal da sexualidade ativa dos homens e a da passividade/ pureza das mulheres (Giffin, 1991, 1994). Fica claro para estes jovens o fato de que estão sendo criticados em decorrência da adesão a valores que apregoam publicamente virilidade e potência de um 'garanhão'. Tais críticas são provenientes das circunstâncias afetivas em que as meninas reivindicam uma nova representação masculina, fora dos padrões de estereóti po. Interessante notar nas falas que, apesar de afirmarem tais estereótipos como definição para ser homem, preferem afirmar que não reproduzem esses modelos.

Percebe-se, então, que o caráter do homem é avaliado de acordo com a maneira como se apresenta no mundo externo, público, da rua, e da forma como mostra o seu desempenho sexual na esfera privada, no mundo individual, entre quatro paredes. Em adição, observamos que a representação do ser homem continua a ser aquela que mostra que o homem aprende o sexo na rua - seu domínio -, ao passo que a mulher o faz em casa, com ele. Este contexto não é aceito sem críticas; apresenta-se cheio de contradições, um ir e vir dos modelos e estereótipos pré-concebidos, que demonstram uma insatisfação de um jovem homem com a imagem que precisa transmitir dele mesmo: o impulso agressivo e ativo sexualmente como referência de masculinidade.

Ter uma esposa também é visto como uma norma cultural que determina o que é ser homem; casar, neste sentido, está representado como um rito de passagem para a fase adulta, muito almejada por estes jovens. Para alguns, ter uma mulher que será mãe de seus filhos está colocado como uma posição que constitui status, sucesso, aceitação e dominação, tanto em relação a outros homens, quanto em relação às mulheres, como se ressaltasse um aspecto da essência da masculinidade.

A identidade de gênero masculina, para os nossos entrevistados, passa pelo comportamento heterossexual e por toda uma construção oposta ao que se entende por feminino. Essa representação evidencia conflitos, principalmente para os que se auto-identificam homossexuais, pois o que se convencionou chamar de homossexualidade caracteriza-se por um contexto presente na construção da identi- 
dade como al go que é negado moralmente, cujo simbólico está reproduzido como um emblema que reflete aspectos de passividade, feminilidade, um homem que não deu certo. $O$ que proporciona conflitos e auto-estima muito baixa, entre aqueles que fazem sexo com homens e se auto-denominam homossexuais.

Para nossos informantes que se relacionam sexualmente com homens, a trajetória para se chegar à posição de homossexual é aquela por meio da qual se vai aprendendo a adaptar-se e incorporar os significados da diferença sexual na vida cotidiana. Tal construção se apresenta cheia de percalços e dúvidas em razão da heterossexualidade imposta socialmente pelo estereótipo do gênero masculino. Nesse sentido, é complexo o processo de construção de uma identidade livre da socialização à qual os sujeitos são submetidos.

Nossos entrevistados explicitam em suas falas o quanto a construção da homossexualidade tem a conotação negativa de um estilo de vida que contraria as expectativas do que é ser homem, percebido por um sujeito que se relaciona sexualmente com outros homens e, portanto, vê-se dividido, fragmentado entre sua identidade sexual e sua identidade de gênero.

Observamos que a bissexualidade é vivida numa situação de baixa estima e que também está construída segundo o conceito de desvio, anormalidade, pois tem como parâmetro a mesma percepção do ser homem baseada culturalmente em princípios ditos heterossexuais.

Enfim, quando utilizam a palavra homem parecem estar se referindo ao tipo de escolha sexual em que o exercício viril continua ditando as regras nas relações masculinas. A heterossexualidade é considerada hegemônica e dada pela natureza, conforme percebemos nas falas. Não se escolhe ser heterossexual: simplesmente se é, como uma referência ao comportamento para o homem. A heterossexualidade, então, passa a ser a expressão indissolúvel de seu modo característico de ser ativo.

Percebemos, sem muita dificuldade, que, apesar dos anos de convivência com a pandemia, a proximidade com a Aids não resultou em efetiva autoproteção, mas numa vulnerabilidade ainda considerável em relação a ela. 0 risco para as doenças sexualmente transmissíveis não sofreu alteração significativa entre esses jovens masculinos que iniciaram sua vida sexual no contexto da epidemia, apesar de afirmarem terem mudado o comportamento.

Observamos nas falas que a questão da Aids evidencia preocupação e medo, mas não leva a uma efetiva proteção. A informação no que diz respeito à prevenção e a aspectos bási- cos sobre a transmissão é relativa. Apesar disso, o sujeito reconhece os equívocos de relacionar a epidemia aos homossexuais. Para alguns, as preocupações sexuais giram em torno da gravidez e da fidelidade, pois quando se considera a parceira ou o parceiro fiel, não se usa a camisinha.

Apesar de o uso da camisinha estar presente nas suas vidas sexuais, isso parece estar mais relacionado ao poder de controle que ela pode oferecer sobre a reprodução e a fertilidade feminina. Além disso, observamos também que a dificuldade de acesso à camisinha no contexto da sedução sexual leva-os a ter relações sexuais sem se proteger devidamente.

A Aids é uma questão em suas vidas e apresenta-se como tendo sido impactante para esta geração. Ao relatarem os tipos de mudanças ocorridas, observamos que a diminuição do número de parcerias sexuais se faz evidente, aspecto ressaltado em campanhas nacionais televisivas realizadas pelo governo. $O$ fato é que este aspecto da prevenção, assim como o modelo de relação Aids e grupo de risco, é um equivoco que parece calcificado, pois a diminuição de parceiros sexuais ou a sua sel eção não representa uma clara definição do problema.

Quando esses jovens dizem saber alguma coisa sobre a Aids, o que se observa é que esse conhecimento é relativo. De maneira geral, não são capazes de assumir na prática sexual as informações que dizem ter. A síndrome apresenta-se como um problema ainda não corriqueiro, apesar de despertar medo ou paranóia, sentimentos que podem representar um momento de alienação em relação à questão; quando muito, referem-se à doença ao falarem sobre os relacionamentos sexuais casuais, negligenciando a prevenção nos relacionamentos fixos.

Consideramos que a eficácia da informação sobre a Aids e os riscos de contágio parece depender de outros fatores que não o teor racionalizador do conhecimento sobre as formas de transmissão do HIV. Assim, percebemos que a motivação para a prevenção da síndrome não é remota, nem se trata de uma questão para os outros, mas algo presente, que pode ser capaz de fazer mudar. Prova disso é a vontade que manifestam de fazer o teste anti-HIV e o medo da possibilidade de serem infectados, aspectos esses observados nos vários relatos de nossos entrevistados.

Percebemos também que as doenças sexualmente transmissíveis, como condiloma e gonorréia, são freqüentes e aceitas naturalmente, tratadas nas farmácias com o acompanhamento 'clínico' do farmacêutico ou de um amigo, até que se resolva o problema. 


\section{Conclusões}

Num âmbito mais geral, podemos concluir que representações de sexualidade(s) estão surgindo e se desenvolvendo no processo de aparecimento da Aids. Neste sentido, a experiência erótica masculina pode fornecer fundamentos para a elaboração de estratégias que irão promover a prevenção. Preservativos masculinos estão sob controle do homem, e não da muIher; neste sentido, prevenção articula-se com gênero. Ou seja, o debate preventivo deverá lidar com os aspectos de gênero, menos como uma barreira à elaboração de novos métodos e mais como uma luz que venha colocar o tema da erotização das práticas sexuais seguras para o HIV/Aids, de maneira explícita, em campanhas públicas que trabalhem a questão dos papéis sociais legados a homens e mulheres, tendo como base suas implicações políticas dentro de um amplo contexto educacional.

Percebe-se que as mudanças em tempos de Aids abrangem fatos mais amplos, como a cultura sexual, e menos específicos, como é o caso das relações sexuais em si. Isto é, ao revisitarmos o conceito de homossexualidade, heterossexualidade e bissexualidade masculina observamos que, tanto no espaço público, quanto no espaço privado das relações sexuais, os sujeitos assim classificados não apresentam respostas padronizadas diante da ameaça da síndrome. Assim, homens, 'machos', heterossexuais, 'veados', 'bichas', homossexuais, 'boiolas', entre outras classificações que tentam identificar aquele que está coletivamente dentro da 'norma' e quem se estabelece fora ou dentro dela de outra maneira, informam-nos que viver plenamente a sexualidade é perceber-se dentro de um contexto de satisfação erótico-afetiva, no qual há poderes desiguais e hierarquias antagônicas (Costa, 1992).

Apesar da complexidade e pluralidade que caracterizaram as identidades dos sujeitos aqui envolvidos, tentamos estabelecer, como exercício de conclusão, algumas análises mais gerais, em nível dos estereótipos dos gêneros e da sexualidade:

- a cultura do machismo se faz presente e organiza ideologicamente os relacionamentos sob a ótica masculina;

- todos os entrevistados demonstram atitudes que oscilam entre o estereótipo masculino e comportamentos críticos em relação a eles;

- vêem a sexualidade feminina e masculina como tendo sido configurada segundo uma divisão natural e biológica;

- a sexualidade masculina é percebida e vivenciada como algo quase incontrolável, en- quanto a sexualidade feminina é percebida como um objeto do controle masculino;

- a noção de homem é a que o vê como aquele que deve começar a atividade sexual bem jovem; é 'natural' o homem ter múltiplos parceiros sexuais, tanto antes, quanto depois do casamento;

- a 'brincadeira de sacanagem' está ligada à transgressão às 'normas'; isto também dá muito prazer e está intimamente ligado à prática sexual anal e aos rituais de 'meinha' ou 'trocatroca' com outros homens;

- a prática sexual está permeada por condutas hierarquizadas de relações de poder: no âmbito dos relacionamentos homossexuais, as dimensões da prática sexual 'ativa' e 'passiva' reproduzem aspectos que norteiam status e poder do gênero masculino; na esfera dos relacionamentos heterossexuais, as mulheres exercem pouco ou nenhum direito relativo à expressão sexual masculina, enquanto os homens detêm maior poder no controle do comportamento sexual das mulheres;

- acreditam esses sujeitos que a prática sexual deve ser desempenhada, na medida em que os papéis masculinos que legaram da cultura impossibilitam-nos de dizer não.

Ao destacarmos alguns aspectos relacionados à questão da Aids, podemos afirmar que todos os jovens mostram um relativo conhecimento sobre o assunto. Algumas questões sobressaíram como aspectos que consideramos relevantes, que podem ser indicadores a se discutir no contexto preventivo da epidemia. Ao entendermos a organização social e cultural dos relacionamentos entre ambos os gêneros e as formas como as noções de gênero são estruturadas, também podemos ser levados a vislumbrar as possibilidades de melhor difusão da prática do sexo seguro. Este pode ser um elemento-chave para se pensar criticamente os papéis sexuais e as formas como os sujeitos os vivenciam.

Percebemos que os mais identificados, no início, com a transmissão da epidemia (os homossexuais) são justamente os que apresentam melhor percepção do risco hoje. Ao contrário, os sujeitos inscritos dentro de um leque de possibilidades 'morais-sexuais' (os chamados heterossexuais masculinos) são os que demonstram maior inconsistência na redução do risco para o HIV/Aids, o que não significa afirmar que a síndrome não tenha tido algum impacto em suas vidas. Mas o que chama atenção nos primeiros éque parecem demonstrar, por meio de sua identidade, um mesmo imaginário político: a homossexualidade projeta o momento de totalização da identidade coletiva, isto é, a 
generalização social a partir de uma identidade particular e vice-versa. Identificando-se com os riscos, se sensibilizam com a necessidade de prevenção. Mesmo assim, o homem nunca deve dizer não ou controlar sua sexualidade, o que faz com que nem sempre use camisinha.

Com base nos relatos de nossos informantes, percebemos por que a Aids se expande, atualmente, principalmente entre os sujeitos auto-identificados como heterossexuais. Ela representa, para estes nossos informantes que iniciaram sua vida sexual em contexto de epidemia, uma preocupação evidente, e a principal atitude ressaltada no que diz respeito à prevenção é o uso da camisinha. Mesmo assim, esta aparece negligenciada no contexto das relações afetivas e regulares, destacando-se, entre os heterossexuais, mais como prevenção à gravidez. Além disso, as representações que têm sobre a mulher neste contexto onde se evidencia maior negligência do sexo seguro e onde as relações são regulares também apresentam-se como um problema, explicitando que a cultura de gênero deve ser relativizada no discurso preventivo.

Em resumo, a tentativa deverá se voltar, para intervir não na mudança do comportamento sexual em si, mas nas formas como os sujeitos concebem as suas relações sexuais, na maneira como as vivenciam e percebem as situações de vulnerabilidade a que as doenças sexualmente transmissíveis - entre elas o HIV/ Aids - expõem-nos. A questão agora é saber: onde a construção da sexualidade se insere, ou seja, em que representação, símbolo, análise, ordem, norma, visibilidade dos discursos e práticas sexuais relatadas; o que é o sujeito sexual e em que medida esta hipotética redefinição resultou em algum avanço moral, para que, assim, quem sabe, os sujeitos percebam a Aids com uma doença que pode ser evitada dentro de uma ampla conscientização política sobre o mundo, a sociedade, a cultura, o corpo, o sexo e o que fazemos com ele.

É evidente que, entre os aspectos dos padrões culturais que foram observados, o fato de os sujeitos transitarem pelas práticas sexuais nos leva a crer que a prevenção deve levar em conta diversos grupos e comunidades, com base em estratos sócio-econômicos, criando metodologias que abordem não apenas as questões específicas dos comportamentos de risco relativos ao HIV/Aids, mas também problemas mais gerais existentes em nossa sociedade, tais como desigualdade e injustiça social, estigmatização e discriminação sexual, mobilização comunitária, a fim de se reduzir a vulnerabilidade social, não só ao HIV/ Aids, como também a todas as questões de cidadania. Isto se justifica pelo fato de esta epidemia traduzir-se em um acontecimento social total, pois envolve questões amplas de nossa cultura.

Ao lidar com questões que envolvem a sexualidade de jovens, observamos que parece haver um certo silêncio que separa as regras rompidas pela própria sexualidade praticada no cotidiano. Assim, a prática sexual é algo para ser feito dentro de um contexto velado e clandestino, está sempre no lugar do proibido e, portanto, das quatro paredes, uma coisa confidencial, pois está cheia de misteriosas questões ainda desconhecidas, mas muitas vezes já vivenciadas (Paiva, 1994). Sexo antes do casamento, incesto, homossexualismo, estupro, prostituição, aborto, gravidez, orgasmo, virgindade, doenças sexualmente transmissíveis fazem parte do script da experiência sexual e do silêncio de muitos jovens, principalmente dos que moram em comunidades de baixa renda.

É obvio que o trabalho preventivo com jovens de baixa renda nos impõe desafios. Entre eles o fato de os jovens estarem em movimento, isto é, suas vidas estão marcadas por inúmeras prioridades e a questão da prevenção da Aids está longe de ser aferida como uma reflexão em si, aspecto muito compreensível. Os problemas relacionados à sobrevivência coloca-os frente a frente com a necessidade de ganhar dinheiro muito cedo. Os constantes problemas familiares associados ao uso indiscriminado da bebida e de outras drogas ilícitas, a baixa escolaridade, o desemprego e o subemprego oferecem a alguns jovens pouca expectativa na sua própria vida, pouco estímulo e baixa auto-estima. Todas estas questões condicionadas a um ambiente de violência nos coloca diante de uma realidade que tem exigido muita criatividade e perspicácia para o desenvolvimento de atividades sistemáticas que venham fazer com que os jovens permaneçam numa proposta de solidariedade específica focalizada na prevenção da Aids.

Enfim, o jovem sabe que seu silêncio sobre o sexo encobre toda uma fundamentação crítica sobre a moralidade sexual que el e vivencia. Neste sentido, os trabalhos a serem desenvolvidos no contexto da prevenção da síndrome para jovens de baixa renda deve observar as noções, os simbolismos e as influências na construção da representação do sexo e quais são os seus maiores legitimadores no local (a religião, a família, a vizinhança, a etnia, o partido político, a comunidade?). Isto porque entendemos que a cultura determina o que é a 'moral sexual' para tentar mostrar o que pode ser a 'realidade do sexo'. 
Entendemos que é fundamental, ao trabaIhar com prevenção, buscar (des)cobrir o que é real no cotidiano da sexualidade e o que é ideal, colocado pelas ideologias dominantes e pelos discursos conservadores. Pode-se considerar que trabalhar com o real é levar em conta que a imaginação sexual não é utópica, portanto nada mais resta na prática sexual para ser inventado, a não ser o exercício do

\section{Referências}

AYRES, J. R. C. M., 1996. HIV/Aids e Abuso de Drogas entre Adolescentes: Vulnerabilidadee Avaliação de Ações Preventivas. São Paulo: Casa de Edição, Departamento de Medicina Preventiva da Faculdade de Medicina da Universidade de São Paulo.

COSTA, J. F., 1992. A Inocência e o Vício: Estudos sobre o Homoerotismo. Rio de Janeiro: Relume-Dumará.

DANIEL, H. \& PARKER, R., 1991. Aids, a Terceira Epidemia: Ensaios e Tentativas. São Paulo: Iglu.

GI AMI, A., 1994. De Kinsey à Aids: a evolução da construção do comportamento sexual em pesquisas quantitativas. In: Aids e Sexualidade: O Ponto de Vista das Ciências Humanas (M. A. Loyola, org.), pp. 209-240, Rio de Janeiro: Relume-Dumará.

GIFFIN, K., 1991. Nosso corpo nos pertence: a dialética do biológico e do social. Cadernos de Saúde Pública, 7:190-200.

GIFFIN, K., 1994. Esfera da reprodução em uma visão masculina: considerações sobre a articulação da produção e da reprodução, de classe e de gênero. Physis, 4:23-40.

HEILBORN, M. L., 1994. De que gênero estamos falando? Sexualidade, Gênero eSociedade, 1:1-8. desejo de cada um. Se conseguirmos canalizar este desejo individual, criando um sentido de solidariedade coletiva e consciência política em relação ao fato de os riscos de infecção do HIV/Aids serem um problema comunitário, talvez possamos obter maior êxito, ou seja, colocar a discussão da prevenção no contexto de um amplo debate por direitos e cidadania.

MINAYO, M. C. S., 1993. O Desafio do Conhecimento: Pesquisa Qualitativa em Saúde. 2a ed., São PauIo/Rio de Janeiro: Hucitec/ Abrasco.

PAIVA, V., 1994. Sexualidade e gênero num trabalho com adolescentes para prevenção do HIV/Aids. In: A Aids no Brasil (R. Parker, C. Bastos, J. Galvão \&J. S. Pedrosa, orgs.), pp. 231-250, Rio de Janeiro: Relume-Dumará.

PARKER, R., 1991. Corpos, Prazeres e Paixões: A Cultura Sexual no Brasil Contemporâneo. São Paulo: Best Seller.

PARKER, R., 1994. A Construção da Solidariedade: Aids, Sexualidade e Políticas no Brasil. Rio de Janeiro: Relumé Dumará.

PARKER, R.; HERDT, G. \& CARVALHO, M., 1995. Cultura sexual, transmissão do HIV e pesquisas sobre Aids. In: Aids, Pesquisa Social e Educação (D. Czeresnia, E. M. Santos, R. H. S. Barbosa \& S. Monteiro, orgs.), pp. 46-64, São Paulo/Rio de Janeiro: Hucitec/ Abrasco.

SCOTT, J., 1989. Gênero: Uma Categoria Útil para a Análise Histórica. São Paulo: Columbia University Press, no 4, Tradução SOS Corpo. 